\title{
SOBRE A AUTONOMIA DAS NOVAS \\ IDENTIDADES COLETIVAS: alguns \\ problemas teóricos
}

\author{
Myrian Sepúlveda dos Santos
}

Identidade e memória

Embora o termo identidade tenha sido popularizado na década de 50 por Erik Erickson em conexão ao sentido individualizado de self (Gillis, 1994), evidentemente a referência a aspectos comuns capazes de associar ou dar sentido a um grupo de pessoas ao longo do tempo e do espaço tem sido explorada desde a primeira metade deste século por abordagens funcionalistas e estruturais desenvolvidas por cientistas sociais. De acordo com teorias marxistas, weberianas ou durkheimianas, definia-se a identidade de um grupo de acordo com o posicionamento de seus membros em relação ao antagonismo entre capital e trabalho, com a renda e status adquiridos, ou de acordo com representações coletivas socialmente consolidadas. Conceitos tradicionais das ciências sociais, no entanto, tornaram-se insuficientes para a explicação da pluralidade de novos movimentos sociais, dos desafios que colocam às identidades com que até então eram associados e da diversidade de questões que levantam na legitimação de suas reivindicações.
A partir da década de 60, uma série de estudos, entre os quais destaco os de Erving Goffman (1959), priorizou a investigação das interações ocorridas entre atores sociais na vida cotidiana e as construções resultantes destas interações. Desta nova perspectiva, passou-se a afirmar que indivíduos constroem suas identidades e que a manutenção destas identidades depende do processo resultante das interações mantidas por estes indivíduos no processo de compreensão de si próprios e de suas intervenções na realidade. Identidades coletivas passaram a ser compreendidas a partir não só de um agregado de interações sociais, mas também da razão políticoestratégica de atores sociais. 1 Nas últimas duas décadas, podemos considerar como sendo quase um senso comum a idéia de que identidades coletivas são construções políticas e sociais e que devem ser tratadas como tal. Afinal, se identidades são construídas, a que interesses elas servem e quem são aqueles excluídos do processo? 2

A noção de identidade, que rompe com as dicotomias entre indivíduo e sociedade, passado e presente, bem como entre 
ciência e prática social, está tão associada à idéia de memória como esta última à primeira. O sentido de continuidade e permanência presente em um indivíduo ou grupo social ao longo do tempo depende tanto do que é lembrado, quanto o que é lembrado depende da identidade de quem lembra. Da mesma forma que a identidade, a memória também deixou de ser pensada como um atributo estritamente individual, passando a ser considerada como parte de um processo social em que aspectos da psique se encontram interligados a determinantes sociais. A memória deixou, portanto, de ser considerada como fenômeno individual, passando a elemento constitutivo do processo de construção de identidades coletivas.

Um interesse crescente pelo tema da memória coletiva pode ser observado a partir da década de 80. $\underline{3}$ É compreensível, portanto, que os trabalhos de Maurice Halbwachs sobre memória coletiva (Halbwachs, 1925, 1939, 1941 e 1950) tenham sido apropriados pelos diversos estudos que procuravam romper com a dualidade entre indivíduo e sociedade. Embora seja bastante utilizado por aqueles que procuram um amparo teórico para a investigação de processos interativos responsáveis pela construção de identidades coletivas, Halbwachs priorizou em seu trabalho a análise de quadros sociais da memória ou representações coletivas, ainda que o processo de construção de memórias coletivas por grupos sociais fosse considerado. É necessário destacar que, como admirador e discípulo de Émile Durkheim, Halbwachs deu primazia ao social em suas análises, negligenciando muitas vezes a possibilidade de investigação das ações e interações sociais. Evidentemente, não se trata aqui de reiterar a ênfase de Halbwachs no social, mas, diferentemente, de retomar questões levantadas por ele sobre a memória que acabam por tornar problemática a nova autonomia que tem sido atribuída, contemporaneamente, ao ator social e aos processos de construção de identidades coletivas.

Até que ponto somos nós, atores sociais, senhores absolutos no controle de nossos comportamentos, nosso passado e nossas identidades? Será que os limites da reflexividade moderna podem ser compreendidos a partir de um novo diagnóstico da modernidade, em que indivíduos, ao se confrontarem com uma grande possibilidade de escolha entre caminhos alternativos, passam a agir exclusivamente com base no conceito de risco, como tem sido defendido recentemente por Ulrich Beck (1996 [1986]) e Anthony Giddens (1990)? Estarão os limites à ação racional basicamente circunscritos à nossa incapacidade de evitar o acidental e imprevisível? Não tenho o intuito de apresentar um conceito alternativo do que seja experiência moderna, reflexividade ou subjetividade, nem de elaborar nova crítica ao conceito de identidade. A percepção de Beck sobre transformações históricas recentes e sua relação com um novo tipo de comportamento humano, bem como os limites impostos a ele, parece responder a inúmeras questões até então precariamente explicadas. Não é por acaso que os conceitos de reflexividade e risco têm sido utilizados de forma marcante por inúmeras correntes teóricas da Sociologia contemporânea. Gostaria, no entanto, de problematizar a leitura corrente de que os limites à nova forma de agir no mundo estariam associados, basicamente, à impossibilidade de controle dos resultados práticos das ações sociais. Utilizo, para isso, algumas das contribuições deixadas por Halbwachs em sua análise sobre memórias coletivas.

Há, atualmente, uma tendência crescente nas ciências sociais de desqualificar e mesmo ignorar trabalhos realizados há mais de cinco anos, que parecem não encontrar espaço de diálogo em uma nova agenda de prioridades. Aparentemente, esta postura justificar-se-ia pelo surgimento de transformações sociais tão singulares e radicais, que somente uma nova proposição teórica poderia dar conta do observado. Meu interesse por Halbwachs vai de encontro a esta postura, pois concentra-se no resgate de questionamentos formulados durante a primeira metade deste século. Ainda que privilegiando a importância de considerarmos movimentos, processos e transformações históricas, acredito que haja questões de períodos históricos distintos cujas proposições centrais tenham tradução em nosso tempo.

Como explicar a memória? Poderíamos dar a ela uma dimensão intermediária entre natureza e espírito, corpo e mente, indivíduo e sociedade? Por que temos consciência 
de que esquecemos, se o que esquecemos não faz parte de nossas memórias? Estas são perguntas atuais que, no entanto, têm sido formuladas ao longo da história. Para Santo Agostinho (1961), somos conscientes de nossos esquecimentos porque a totalidade da vida é Deus e o divino está em nós. Muitos séculos depois, o filósofo Henri Bergson (1985 [1939]), procurando responder a esta mesma questão, afirmou que o tempo real, durée, existe em nossas memórias e nelas pode ser compreendido. Halbwachs optou pelo estudo de quadros sociais para explicar a memória, procurando uma alternativa não só à abordagem filosófica de Bergson como também à de diversos pensadores de sua época, como James Joyce, Marcel Proust, William James e Sigmund Freud, que estavam todos, à sua maneira, voltados para a memória como meio do conhecimento.

Neste artigo, meu interesse é basicamente resgatar duas questões teóricas levantadas por Halbwachs: a antecedência dos quadros sociais da memória e a presença de lugares físicos e espaciais da memória coletiva. Estas são questões que nos pemitem compreender que há aspectos inerentes a memórias ou identidades coletivas que estão fora do alcance tanto da capacidade reflexiva do ator social, como das lógicas inerentes às construções simbólicas a que temos acesso. Em que pese a tentativa de analisar a sociedade através de uma perspectiva funcionalista, Halbwachs abriu diversos caminhos que nos possibilitam pensar, hoje, a convivência e simultaneidade entre experiências associadas a períodos históricos distintos. Distante da visão a-histórica e sociologizante com que foi categorizado durante décadas, seu trabalho deixou questões fundamentais a este final de século. Sem desqualificar o poder analítico da razão, acredito que são os limites impostos a ela que representam o diferencial importante para sua compreensão. É a percepção destes limites no processo de construção de novas identidades coletivas que nos torna capazes de considerá-las não-essencialistas e eticamente responsáveis por legados de opressão e esquecimento, que podem estar ausentes tanto do discurso deixado por gerações passadas, quanto de movimentos sociais atuantes no presente.

\section{Os quadros sociais e a memória coletiva}

[...] a memória individual não épossivel sem instrumentos, como palavras e idéias, os quais não são inventados pelos indivíduos, mas tomados emprestados de seu meio.

Se as imagens do presente fundem-se estreitamente com as lembranças do passado, e se as imagens parecem emprestar às lembranças sua substância, éporque nossa memória não é como uma tábula rasa.

(Maurice Halbwachs)

Halbwachs foi um dos autores que mais contribuiu para a compreensão do significado da memória coletiva. Viveu em Paris no início do século e foi um profundo conhecedor do debate filosófico da época. Após sua formação acadêmica inicial como discípulo de Bergson, debruçou-se sobre os trabalhos não publicados de Leibnitz. Mais tarde, renunciou completamente às assertivas filosóficas de seu tempo e procurou uma nova inspiração teórica no trabalho do sociólogo Émile Durkheim, de quem se tornou colaborador. ${ }^{4} \mathrm{O}$ primeiro trabalho acadêmico por que ficou conhecido foi sobre classes sociais, onde já defendia o argumento de que a identidade atribuída a trabalhadores não poderia ser apontada apenas a partir da forma de inserção de determinados grupos sociais na atividade econômica.

Desde sua nomeação como professor da Universidade de Strasbourg, Halbwachs dedicou-se ao estudo da memória e foi, de fato, o primeiro scholara enfatizar o caráter social da memória. Há mais de 70 anos ele afirmou que tudo o que nos lembramos do passado faz parte de construções coletivas do presente. Um de seus grandes méritos foi ter escrito sobre memória coletiva numa época em que a memória era compreendida primordialmente como fenômeno individual. $\underline{5}$

Les cadres sociaux de la mémoirefoi publicado em 1925 e representa, ainda hoje, um dos trabalhos mais importantes sobre memória coletiva com que podemos contar. Neste livro, Halbwachs esbeleceu os princípios fundamentais de uma teoria sobre memória que foi desenvolvida empírica e teoricamente em obras posteriores. Em 1939, escreveu um ensaio sobre a memória coletiva de músicos, afirmando que 
estes só conseguem lembrar e reproduzir partituras musicais porque carregam consigo padrões adquiridos socialmente. Segundo Halbwachs, uma parte das lembranças que os músicos têm dos sons, e que os possibilita identificar, decifrar e executar músicas, conserva-se em uma memória coletiva que está presente em um sistema de signos fixado no tempo e espaço social. Dois anos mais tarde, desenvolveu um estudo empírico sobre memória coletiva, La topographie légendaire des évangiles en Terres Saintes, no qual apresentou uma grande contribuição ao estudo da memória e da identidade, que só recentemente tem sido devidamente reconhecida. Seu quarto escrito sobre memória, La mémoire collective, foi publicado em 1950, após sua morte no campo de concentração de Buchenwald.

Para Mary Douglas (1985), que editou La mémoire collectivenos Estados Unidos, esta obra, ainda que incompleta, é brilhante, principalmente no que diz respeito a suas observações sobre história e memória. Alguns autores (Namer, 1987) fazem uma forte distinção entre o primeiro trabalho de Halbwachs (Les cadres...) e os demais, atribuindo àquele uma abordagem mais positivista ou funcionalista, em contraposição aos estudos posteriores sobre memória coletiva. Separam, portanto, o social, que seria relativo à sociedade como um todo genérico, do coletivo, que representaria grupos específicos em interação (Namer, 1987). Embora seja inegável que a ênfase no cultural e no simbólico esteja mais explicitada em trabalhos posteriores (Halbwachs, 1939, 1941 e 1950), não considero que haja uma ruptura entre o primeiro e os demais trabalhos do autor, mas sim um contínuo aprofundamento das idéias e pensamentos consolidados em 1925. Um de meus objetivos centrais ao investigar o trabalho de Halbwachs é procurar justamente resgatar a simultaneidade com que podemos perceber os quadros sociais da memória e os processos intersubjetivos de construção de memórias coletivas.

A afirmação central de Halbwachs sobre a memória é a de que, quaisquer que sejam as lembranças do passado que possamos ter - por mais que pareçam resultado de sentimentos, pensamentos e experiências exclusivamente pessoais —, elas só podem existir a partir dos quadros sociais da memória (Halbwachs, 1925, p. XVI). Esta tese, longe de ignorar que indivíduos têm memórias e, portanto, de aniquilá-los do processo de construção de memórias coletivas, estabelece um argumento muito interessante, e sobre o qual eu me deterei a seguir, acerca da antecedência de quadros sociais da memória.

Halbwachs nos relata o seguinte caso: ao ir a Londres pela primeira vez, embora sozinho, visitou diferentes lugares e pessoas. Ao retornar a Paris, trouxe com ele diversas lembranças de Londres que se remetem apenas à sua "perambulação" pela cidade, enfim, a fatos, imagens, tragédias que não teve com quem partilhar. Será possível, pergunta-se ele, que, ainda assim, as lembranças que tenho de Londres sejam só minhas? Não estariam os escritos de Dickens em minha mente quando visitei Londres pela primeira vez? Não estariam estes escritos comigo em minhas recordações? A associação entre dois contextos distintos foi feita através de um livro, ou seja, da escrita, da informação.

Esta é uma reflexão atualíssima e que o aproxima deste final de século de forma impressionante; é uma questão a que toda abordagem da construção contemporânea de identidade ou memória coletiva necessita considerar. Até que ponto o "monitoramento reflexivo" — se o considerarmos como condição moderna da percepção de nossas lembranças pode ignorar o fato de que nossas escolhas, reações, hábitos foram sendo constituídos a partir de nosso relacionamento com representações coletivas, como aquelas que aparecem no livro de Dickens sobre as paisagens de Londres? Halbwachs, ao considerar os quadros sociais da memória, está levantando a questão da presença do "outro genérico" em nossa percepção da realidade, em que não apenas a co-presença é um prérequisito de constituição de identidade. Portanto, mesmo sem presenciar as revoluções tecnológicas e informacionais com que vivemos recentemente, o autor, ao destacar a influência dos escritos de Dickens sobre a forma pela qual ele foi capaz de reconhecer Londres, mostrou a importância da informação como mediadora do processo de construção de identidade. Se passarmos a compreender que nossas lembranças relacionam-se a quadros sociais 
mais amplos, compreendemos também que o passado só aparece a nós a partir de estruturas ou configurações sociais do presente, e que memórias, embora pareçam ser exclusivamente individuais, são peças de um contexto social que não só nos contém como é anterior a nós mesmos.

Mas, como compreender individualidade e diferença se acreditamos que há um campo básico de significações que antecede a todos nós? A individualidade faz sentido e não se contrapõe a quadros sociais se a pensamos como construção. Desde Les cadres..., Halbwachs já afirmava que nós construímos nossas memórias como membros de grupos sociais determinados e que, neste processo, obrigatoriamente utilizamos as convenções sociais disponíveis a nós. Indivíduos não se lembram por eles mesmos, isto é, para lembrarem, eles necessitam da lembrança de outros indivíduos, para confirmarem ou negarem suas lembranças, que por sua vez estão localizadas em algum lugar específico no tempo e no espaço. Ao ressaltar o caráter social da memória e explicar que nem mesmo as memórias mais íntimas podem ser pensadas em termos exclusivamente individuais, Halbwachs enfatiza tanto o caráter social quanto interativo da memória. Para ele, todas as nossas lembranças relacionam-se, portanto, com a vida material e moral das sociedades.

Aquele que relembra um tombo ocorrido na infância, por exemplo, ainda que não tenha tido testemunhas, e que pense ser esta uma lembrança exclusivamente sua, tem associado a esta lembrança o lugar do presente de onde ele se lembra, como também os antecedentes, os relatos posteriores, a reação de outros — real e imaginária — enfim, uma série de situações a partir das quais o tombo foi construído e reconstruído. A lembrança é resultado do convívio do indivíduo com outros indivíduos. Esta rede de relações e interações está presente na memória que cada um guarda como "exclusivamente" íntima e pessoal.

Para o sociólogo francês, portanto, não há uma memória coletiva capaz de impor-se ao conjunto de indivíduos arbitrariamente, nem tampouco um quadro social da memória que não seja constituído a partir de um grupo de indivíduos. Fiel ao conceito de representação coletiva durkheimiano, ele não pensa quadros sociais como um somatório de representações individuais. Apesar da concretude ou objetividade atribuída muitas vezes aos quadros sociais da memória, interessa-me enfatizar a percepção de Halbwachs de que a memória não é e não pode ser considerada o ponto de partida, porque ela nunca parte do vazio; a memória é adquirida à medida que o indivíduo toma como sua as lembranças do grupo com o qual se relaciona: há um processo de apropriação de representações coletivas por parte do indivíduo em interação com outros indivíduos

O sujeito constitui-se a si próprio mediante o seu confronto tanto com sua imagem especular, quanto com o "outro", em um processo contínuo de transformação. Aqueles que lembram são os indivíduos, que revisam lembranças fragmentadas e desconectadas de acordo com narrativas consolidadas coletivamente (Halbwachs, 1925, pp. 40-46). Se a memória de um indivíduo é diferente da memória de seu irmão, de seu amigo, isto ocorre porque cada indivíduo confronta-se, durante seu percurso de vida, com uma complexidade única de situações (Halbwachs, 1950, pp. 1517). Indivíduos apresentam, portanto, diferentes comportamentos não porque tenham "personalidades" ou "naturezas" próprias, independentes do social, mas devido às experiências diversas por que passaram (no sentido de construir e incorporar) ao longo de suas vidas. Não se pode eliminar a importância do ator que reconstrói seu passado, nem considerar construções coletivas como autônomas, mas, sim, negar ao indivíduo, ao inconsciente ou à natureza humana independência em relação à sociedade.

Como exposto, o trabalho de Halbwachs explica a individualidade por meio do processo de diferenciação por que passa cada indivíduo em suas múltiplas experiências de vida. Contemporâneo de Halbwachs, ainda que sem nenhum diálogo com ele, o psicólogo inglêssirFrederic Bartlett também estudou memórias coletivas. Sua maior contribuição nesse campo foi propor o conceito de schemas, ou seja, códigos sociais da memória internalizados pelos indivíduos. Bartlett (1961 [1932]) relatou que nativos da tribo Swazi, após visitarem a Inglaterra, lembravam-se de 
gestos, objetos e fatos que, de uma forma ou de outra, já lhes eram familiares. Os nativos lembravam-se do guarda de trânsito inglês porque este levantava a mão de uma forma familiar (os Swazi utilizavam os mesmos gestos para saudarem-se uns aos outros).

O estudo de Halbwachs pode ser vinculado ao estudo de representações coletivas e contraposto aos estudos de Bartlett, que enfatizam o processo psicossocial de reconstrução das memórias. No entanto, ao invés de enfatizar as dicotomias entre essas abordagens, acredito ser mais produtivo observar que muitos são os aspectos em comum entre o trabalho de Halbwachs e estudos do campo

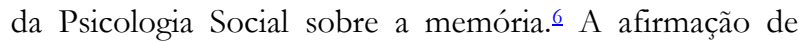
Halbwachs de que indivíduos que têm lembranças devem ser compreendidos como parte de um grupo, como se depreende da passagem "on peut dire aussi bien que l'individu se souvient en se plaçant au point de vue du groupe" (Halbwachs,1925, p. XVIII), faz com que seu trabalho, longe de estar aprisionado à perspectiva da imposição do social sobre indivíduos, possa facilmente ser apropriado e inter-relacionado às abordagens psicossociais, que partem da investigação dos processos interativos de produção de memórias coletivas. Para Halbwachs (1925, pp. 274-275), "em même temps qu'on voit les objets, on se représent la façon don't les autres pourraient les voir: si on sort de soi, ce n'ést pas pour se confondre avec les objets, mais pour les envisager du point de vue des autres [...]". Novamente, aqui está a afirmação de que não há um mundo de objetos, de representações coletivas, que se impõe a nós de forma arbitrária, pois somos nós que o vemos.

$\mathrm{Na}$ linha de Bartlett, há diversas abordagens interacionistas mais recentes, como as do psicólogo Ulric Neisser, que têm denunciado a ineficácia de estudos neurológicos e laboratoriais que não consideram o social e apontado a necessidade de estudar a memória a partir da interação de indivíduos com diversos contextos da vida cotidiana. Esta perspectiva possibilita um maior conhecimento de como as pessoas utilizam suas memórias, isto é, suas experiências passadas, ao enfrentarem os desafios do presente. Também para Neisser (1982a, 1982b, 1990a e 1990b), a memória, por mais individual que possa parecer, não pode ser desvinculada de fatos, histórias e rotinas familiares para ser compreendida.

Halbwachs trabalhou tanto com a antecedência de quadros sociais da memória como com o processo de sua construção, motivo por que tem sido apropriado por aqueles que trabalham a partir da observação empírica e da abordagem interpretativista destes processos. É importante, no entanto, reconhecer que, apesar de afirmar que nenhuma memória pode existir se indivíduos não mantêm vínculos pessoais entre si, Halbwachs jamais identificou-se àqueles que pensavam ser possível associar o estudo da memória exclusivamente à investigação de redes de interações sociais. É dele a afirmativa de que os quadros sociais da memória não são constituídos pela combinação de lembranças individuais, nem mesmo de formas vazias, mas, ao contrário, são os instrumentos de que a memória coletiva se serve para recompor uma imagem do passado que se combina, a cada época, com os pensamentos dominantes da sociedade (Halbwachs, 1925, p. XVIII). Para abordagens interacionistas, quadros sociais devem ser vistos como estruturas vazias, cujo sentido será dado apenas a partir do processo construtivista. Contrariamente a esta perspectiva, Halbwachs enfatizou a importância dos quadros sociais da memória no processo de lembranças e esquecimentos, compreendendo que eles não são apenas produto da reflexividade de atores no presente. Não penso ser possível objetivar o estudo dos quadros da memória, tal como propusera Halbwachs, que também a eles atribuía uma função de coesão social. Mas seus argumentos, se forem desvinculados da perspectiva cientificista e associados a possibilidades de movimento e mudança, procedem, como também procede a sua tentativa de resgatar a possibilidade de estudarmos os lugares da memória social ou coletiva.

Em suma, Bartlett não acreditava que houvesse um sentido imanente em estruturas ou representações coletivas e interessou-se por mostrar como "estruturas" são apropriadas independentemente de qualquer sentido que possamos atribuir a elas. Concluiu que o que importava era o estudo do processo de apropriação não de estruturas, mas de códigos sociais, dando preferência à busca do sentido 
inerente às construções sociais. Halbwachs, apesar de também ter percebido que a reconstituição do passado era realizada por grupos sociais, procurou mostrar que a busca do sentido das construções coletivas deveria se localizar na investigação dos quadros sociais da memória, estruturas, para ele, estáveis e capazes de tornarem-se objetos de uma análise sistemática por parte do cientista social. As diferenças entre os trabalhos de Bartlett e Halbwachs podem ser compreendidas não como diferentes explicações do que seja memória coletiva, mas como diferentes abordagens de um mesmo fenômeno. A questão que se coloca contemporaneamente é até que ponto somos capazes de resgatar o sentido presente seja em processos interativos de construção do social, seja em construções simbólicas derivadas destes últimos. Neste sentido, acredito que possamos compreender melhor memórias coletivas à medida que percebamos os limites impostos por cada uma destas abordagens à possibilidade de exaustão da procura do sentido seja no processo de construção da memória por indivíduos, seja nas estruturas que os contêm.

Se nós pensarmos uma situação em que um recém-nascido é completamente separado do convívio de outros seres humanos e de todos os instrumentos de civilização, tais como linguagem, costumes e tradições, é difícil imaginarmos que imagens do passado esta criança conseguirá reter e que identidade de si própria será capaz de construir. Se indivíduos constroem suas identidades mediante o uso da memória, esta é indissociável, por exemplo, da linguagem, que é uma construção social que antecede a existência destes indivíduos. Por outro lado, na medida em que indivíduos utilizam a linguagem, eles também são parte de sua manutenção e continuidade. Gostaria de ressaltar, portanto, que ao considerarmos a construção da memória, não há como ignorarmos que sempre há elementos determinantes no processo construtivo que se encontram fora do alcance da vontade e do poder reflexivo dos indivíduos. Um dos grandes legados que Halbwachs nos deixou e que procurei enfatizar foi sua tentativa de mostrar a presença de um fator de imprevisibilidade nas construções sociais do presente: a antecedência dos quadros sociais da memória. Em uma época em que as abordagens macroestruturais, ainda que interpretativas, estão cada vez mais em questão, cabe voltarmos a Halbwachs e nos perguntarmos se será possível a compreensão da constituição de identidades sociais sem problematizarmos o sentido de palavras e idéias do presente que as antecedem. A partir de seu trabalho, é difícil ignorarmos que o fator de indeterminação inerente a qualquer ação social não se deve exclusivamente às condições de imprevisibilidade do futuro.

Podemos compreender, portanto, que indivíduos se relacionam com diferentes quadros sociais da memória durante suas vidas, na medida em que vão para escolas, lugares de trabalho, grupos religiosos, espaços de lazer, ou mesmo quando permanecem com suas famílias. Podemos compreender estes quadros em contínuo movimento e reestruturação. Além disso, cada indivíduo traz consigo uma composição única de inúmeras experiências. Não há necessidade, portanto, de pensarmos que a antecedência de quadros sociais da memória implica a imposição de uma representação coletiva, única e homogênea, sobre "mentes" e "corpos". Há várias representações coletivas, conflitivas e em mudança, relativas a diferentes grupos, por meio das quais indivíduos se socializam e constituem suas identidades e memórias ao longo de suas vidas. Podemos, diferentemente de Halbwachs, pensar estes múltiplos quadros sociais de uma forma menos rígida, ou seja, pensálos sempre em contínua transformação, bem como sujeitos a múltiplas apropriações segundo tensões e conflitos inerentes à sociedade.

\section{Tempo coletivo e memória}

Para além desta franja do tempo que se move, ou, mais exatamente, do tempo coletivo, não há nada, pois o tempo dos filósofos não é senão uma forma važia.

(Maurice Halbwachs)

Segundo Hutton (1993, pp. 73-91), das várias analogias trazidas por Halbwachs no seu esforço em explicar o significado de memórias coletivas, aquela em que ele 
descreve as ondas do mar quebrando-se em um litoral rochoso é a melhor. A imagem que ele nos traz é a de que à medida que a maré sobe, as rochas ficam submersas, e à medida que desce, deixa em seu lugar apenas pequenos e esparsos lagos entre as formações rochosas. O mar avançando representa a memória viva, que em seu refluxo deixa pequenos lagos e rochas, ou seja, os lugares da memória, que moldam e contêm o que restou da memória viva. Embora não deixasse de lado os pequenos lagos, foi inegavelmente com as grandes rochas que Halbwachs mais se preocupou. Halbwachs nos mostrou como um conjunto de marcas, objetos e fatos podem fazer parte e mesmo influenciar decisivamente nossas representações do passado.

Também para Halbwachs o passado é sempre reconstruído de acordo com tensões, normas e situações do presente. Acredito que ele tivesse a mesma consciência de tempo real que o filósofo Henri Bergson. Este dedicou seu trabalho ao estudo da memória, compreendendo o tempo atrelado a experiências de vida. O tempo da duréebergsoniana não pode ser medido por nenhuma equação física, e é completamente incompatível com o tempo homogêneo que é utilizado para unir passado e presente através de uma ordenação lógica, contínua e artificial. Bergson (1985, pp. 83-96) trabalhou com a possibilidade de a memória associar-se a diferentes formas de percepção do passado: a que reconhecia imagens do passado a partir da semelhança entre imagens e aquela que estava presente não em imagens, mas na continuidade de hábitos da vida cotidiana. Em primeiro lugar, podemos dizer que uma pessoa, por exemplo, pode lembrar-se de diferentes leituras ou aprendizados de uma mesma lição; ela é capaz de associar cada uma de suas experiências a uma ocasião específica, localizando-a em determinado lugar e época. Estas leituras, passíveis de serem localizadas no tempo e espaço, seriam, para Bergson, experiências únicas. Em segundo lugar, há formas de aprendizado que só podem ser identificadas a partir de nossas performances. Não somos capazes de identificar o momento preciso em que aprendemos a ler, andar de bicicleta ou evitar uma situação de perigo. Diferentes etapas do aprendizado não se separam nestes últimos exemplos. Bergson atribuiu à memória a capacidade de unir estes dois planos de experiência; creditou à memória a capacidade de nos permitir uma consciência espaço-temporal.

Halbwachs procurou este tempo "real", mas sem acreditar que o acesso a ele fosse dado seja pela percepção de indivíduos, seja por qualquer dimensão associada à matéria de que se constitui o mundo real. Neste sentido, afastou-se de Bergson. Ainda assim, continuou trabalhando com um conceito de tempo muito próximo daquele delineado pelo filósofo francês. Atribuiu às abordagens históricas interpretações arbitrárias do passado, por se basearem em um tempo subjetivo e artificial, e propôs o estudo da memória coletiva para dar conta de um tempo real, presente em construções coletivas. Não sabia que, pioneiramente, estava dando os primeiros passos no caminho do estudo historiográfico que posteriormente celebrizou toda uma geração de historiadores franceses e ficou conhecido como o estudo das mentalidades coletivas. 7

Halbwachs reconstruiu a relação entre tempo e memória a partir da afirmação de que a memória era coletiva e de que seria através das representações coletivas que indivíduos perceberiam o passado. Os indivíduos perceberiam o tempo à medida que o percebessem espacialmente, isto é, eles traduziriam experiências diretas em segmentos homogêneos do tempo e os alocariam em uma linha contínua para poderem localizá-los mais tarde. A sensação de temporalidade em todos nós derivaria do fato de que diversos momentos fariam parte de um conjunto de pensamentos comuns a um determinado grupo, de um quadro social da memória. Para ele, portanto, adurée não seria perceptível. Não poderíamos contar com provas escassas da memória viva. O material disponível para nossa percepção do passado estaria nas rochas. A diferença entre lembranças de um passado recente e de um passado remoto explicar-se-ia pelo fato de que a cada lembrança corresponderia um quadro social distinto. Halbwachs utilizou uma metodologia similar àquela usada recentemente pela Antropologia histórica, que procura compreender uma época mediante o estudo da relação entre redes de sociabilidade e estruturas coletivas de 
pensamento. Seu estudo sobre peregrinações religiosas a terras santas (Halbwachs, 1941), em que apresenta os lugares geográficos como portas de entrada para o estudo compreensivo de imagens e comemorações, é hoje um marco na historiografia contemporânea.

Se, para o autor, estudos historiográficos implicavam uma esquematização arbitrária do passado, com seus cortes e períodos artificiais, a memória coletiva apontava para a percepção de quadros sociais associados a uma corrente contínua de pensamento. Como as imagens do passado representariam o resultado da interação entre indivíduos, a história só seria possível no momento em que a memória coletiva deixasse de existir (Halbwachs, 1950, p. 68). Ele contrapôs, desta forma, história a memória. Vários autores contemporâneos trabalham com uma distinção similar, uma contraposição entre uma memória viva e contínua, construída por indivíduos em interação, e uma história artificial, arbitrária e voltada para a tradução do tempo em unidades homogêneas e quantificadas.̂Acredito que não precisamos operar com esta distinção entre história e memória, uma vez que tanto o estudo de memórias coletivas pode ser compreendido como histórico, pois sempre há um grau de arbitrariedade na abordagem das redes de sociabilidade, como abordagens históricas podem ser legitimadas apesar do caráter arbitrário e impessoal de suas interpretações, uma vez que qualquer atividade interpretativa reflete não apenas o presente, mas também as heranças do passado que convivem e determinam o presente. É imprescindível lidarmos com a impossibilidade de uma abordagem científica resgatar o tempo real e, a partir daí, aprendermos a respeitar os limites de cada abordagem teórica. Se indivíduos sempre constroem seu passado de acordo com preocupações e situações estabelecidas no presente, isto não quer dizer que este presente não contenha experiências ou traços do passado incapazes de serem percebidos em sua totalidade.

La topographie aparece como obra percursora de uma série de iniciativas que hoje estão engatinhando no terreno da metodologia e da teoria social. A tese defendida é a de que a Terra Santa bíblica foi um território imaginário, construído durante a Idade Média, na Europa, e sobreposto, mais tarde, ao território da Palestina. Longe de ser uma descoberta, a Terra Santa significou, portanto, o resultado da projeção do imaginário de fiéis cristãos sobre determinado lugar. Este estudo, aparentemente despretensioso, categoricamente definido por seu autor como sociológico e não histórico, representa uma contribuição importante não só para as correntes historiográficas contemporâneas, mas também para todos aqueles que se engajam no estudo de políticas de identidade. O trabalho de Halbwachs nos permite compreender que lugares da memória apresentam um poder - fixo em pedras, monumentos e construções arquitetônicas, mas presente também em rituais e comemorações - capaz tanto de impor a representação de um grupo sobre outros, quanto de abrir um espaço para que grupos oprimidos possam fortalecer suas identidades através da recuperação de traços da memória. Desta forma, embora, segundo o autor, as peregrinações à Terra Santa exercessem o papel crucial de dar continuidade e estabilidade à tradição religiosa cristã, através de seu trabalho podemos compreender que os lugares da memória que ele pesquisou foram palco de disputas travadas por diferentes grupos sociais.

Halbwachs desenvolveu um trabalho minucioso e detalhista sobre as imagens da Palestina, por meio das quais a vida de Jesus foi reverenciada através dos séculos. Podemos dizer que ele fez um trabalho de desconstrução destas imagens. A partir daí, trouxe-nos novas surpresas. Observou que os lugares escolhidos pelos peregrinos cristãos como santificados eram quase todos eles lugares há muito considerados pelo povo judeu como sagrados. Para ele, o quadro social da memória judaica indicava a estrutura mais profunda da memória, capaz de ditar a escolha dos lugares da memória cristã. Procurou mostrar com isso que os quadros sociais da memória - tais como objetos físicos com os quais estamos em contato direto e que se modificam muito pouco — nos fornecem uma imagem de permanência e estabilidade crucial para nossa inserção no mundo. Aprendemos, portanto, que memórias — sejam elas memórias de indivíduos, grupos ou nações — são construídas em relação a um complexo conjunto da vida 
moral e material das sociedades em que indivíduos vivem. La topographie nos mostra, portanto, a importância dos lugares da memória e nos diz que a memória pode existir em referência a estruturas espaciais, resultantes de construções sociais. Não é pouco. A experiência de um tempo fragmentado não pode ser desprezada por uma época que presencia a ruptura dos laços entre gerações, quando avós e netos não compartilham mais o mesmo espaço social e não têm como referência os mesmos quadros sociais. Torna-se plenamente compreensível, portanto, a crescente importância da tentativa de perceber o tempo em sua descontinuidade.

São vários os autores que procuram na memória a capacidade de lidar com experiências adquiridas do passado e transmitidas entre gerações. Alguns voltam-se para a memória involuntária, aurática (Benjamin, 1968), ou ainda para heranças que podem ser encontradas em processos comemorativos, em que significados são mantidos ao longo do tempo (Connerton, 1989). Mas, como vimos, para Halbwachs a memória viva vinculada à duréebergsoniana encontrava-se quando muito isolada em lagos-miniaturas encravados em rochas, e por isso não valia a pena dedicar maiores esforços para ir ao seu encontro. Embora possamos concordar com ele que dificilmente a memória vinculada à intuição possa desempenhar o papel atribuído por Bergson de reunir experiências do passado às do presente, isto não nos leva a considerar que as convenções sociais, sejam elas morais ou materiais, sejam as únicas possibilidades de acesso ao passado. Halbwachs desconsiderou os pequenos lagos da memória por não encontrar neles nenhuma possibilidade de aplicar seus estudos empíricos e matemáticos, mas, infelizmente, não percebeu que não há abordagem científica capaz de dar conta do tempo real a que se reportava: as rochas não estavam tão a salvo da erosão como ele previra.

\section{Ciência e memória}

Como uma sociedade, qualquer que seja, poderia existir, subsistir, tomar conbecimento de si mesma, se ela não considerasse um conjunto de acontecimentos do presente e do passado, se ela não pudesse reconstruir o curso do tempo e recuperar incessantemente os traços que deixou de si mesma?

(Maurice Halbwachs)

Encontro-me diante de um computador escrevendo e reescrevendo frases que jamais me deixam completamente satisfeita com seu sentido. Eu faço e refaço estas frases e chego à conclusão de que por mais que eu escreva, não consigo expressar completamente o que penso. $\mathrm{O}$ resultado é que eu escolho a melhor frase. O mesmo acontece com a memória. Quando eu me lembro de um evento do passado, o faço por meio da reconstrução de uma série de imagens fragmentadas e de um conhecimento acumulado a partir de experiências já vivenciadas. No momento exato em que expresso o passado sob a forma de imagem reconstruída, tal como a frase escolhida, dou ao passado uma localização específica no tempo e no espaço, e à memória, a rigidez que ela não possui; ou então obedeço à experiência adquirida ao longo dos anos, traindo a fidelidade ao passado. Como a imagem lembrada é sempre uma criação do presente, há sempre uma distância entre a imagem construída sobre o passado - em gestos, pensamentos ou ações - e o passado, embora este último não esteja ausente da imagem do presente.

Memórias, imagens, identidades construídas são sempre incompletas porque correspondem a uma multiplicidade de experiências vividas por indivíduos e grupos sociais que não se encontram parados no tempo, mas em contínua transformação. Além disso, há tensões e disputas que resultam em lembranças e esquecimentos diferenciados de acontecimentos vivenciados. Como vimos anteriormente, Halbwachs trabalha com o processo de construção de memórias coletivas e com os quadros sociais da memória. Afirmou a impossibilidade de percebermos completamente o que era inerente ao processo de construções coletivas e desqualificou os estudos que se restringiam a esta perspectiva. Mas será que podemos desqualificar estes estudos? Podemos pensar a distância entre construções e convenções apenas a partir do movimento de diferenciação ocorrido no tempo e no espaço (Halbwachs, 1925), ou apenas a partir de dominações e imposições que se 
sobrepõem às negociações realizadas por atores sociais. ${ }^{2}$ As críticas de Halbwachs colocam limites às abordagens alternativas, sem que sejam capazes de as invalidar por completo. Em relação ao trabalho de Halbwachs, o mesmo se coloca. Há limites a serem considerados em sua abordagem, o que não nos habilita a negligenciar alguns aspectos importantes apontados por ele.

Procurei resgatar dois argumentos trabalhados por Halbwachs em seu estudo de memórias coletivas. Em primeiro lugar, há em sua abordagem uma associação entre memória e sociedade. $\mathrm{O}$ autor compreende que a memória é fruto de interações sociais que ocorrem no presente; de que nestas interações dá-se a constituição da imagem de cada "um" no "outro"; e de que a personalidade dos indivíduos se forma nestes contextos interativos, de forma fragmentada e aberta a múltiplas composições. Esta perspectiva está presente em diversas passagens de seu trabalho. Pare ele, não há um passado oculto a ser descoberto pelo filósofo, nem um passado reprimido a ser liberado pelo psicanalista.

Em segundo lugar, ele compreendeu que a memória, como ato de reconstrução, nunca é idêntica a qualquer imagem do passado, mas que há lugares da memória que podem ser estudados como formas de acesso ao passado. Qualquer sociedade, na medida em que existe, subsiste e toma conhecimento de si mesma, terá os traços que deixou de si mesma reconstruídos. É dele a afirmativa de que as sociedades têm a necessidade do espaço-temporal provido pelos quadros sociais da memória (Halbwachs, 1925, p. 34). Afastou-se, portanto, de Bergson e criticou a possibilidade de que nossas mentes pudessem armazenar toda sorte de impressões e imagens presentes no mundo material. Criticou a noção de inconsciente freudiana como resposta à fragmentação da memória. Mas, o que é a memória para Halbwachs?

O estudante que bloqueia sua memória durante um exame não o faz por problemas mentais ou por características de sua personalidade a serem tratadas; ele bloqueia seu pensamento por condições eminentemente sociais e que podem ser compreendidas como tal. Sem a tensão provocada pelo exame, sua memória estaria perfeita. Afetividade, emoções, características individuais, repressões e intenções, todos estes, para Halbwachs, são aspectos que poderiam ser compreendidos apenas em relação às determinações sociais. A afasia, distúrbio da linguagem, também não poderia ser considerada um problema meramente orgânico, pois surge como resultado de problemas ocorridos na interação entre indivíduos e seus grupos sociais (Halbwachs, 1925, pp. 64-69). Da mesma forma, sonhos não poderiam ser explicados pela liberação de repressões subjetivas. É sua a análise de que sonhos não representam experiências profundas, submersas, que escapam à repressão da consciência durante o sono, ou seja, não são resultado do conflito entre inconsciência e consciência. Imagens presentes em sonhos são imagens coletivas fragmentadas porque, quando dormem, os indivíduos não são capazes de organizar as imagens da mesma forma que o fazem quando estão acordados e em meio a um grupo social. É impossível que indivíduos rememorem fatos enquanto dormem; o que acontece é que eles reconstroem suas lembranças de acordo com imagens coletivas sem contarem com todos os seus sentidos para esta tarefa. O mesmo acontece estejam eles adormecidos ou embriagados.

Halbwachs mostrou a importância do social na constituição da memória, em problemas de linguagem, no significado de sonhos e doenças mentais. Estes são, sem dúvida, argumentos que encontramos em estudos estruturalistas e pós-estruturalistas. Foucault escreveu, décadas depois, sobre a constituição social da doença; Lacan apresentou uma alternativa à interpretação psicanalítica freudiana clássica de inconsciente incorporando a ênfase no social. Em contraposição à dinâmica descrita por Freud, que apresenta a repressão e introjeção de drives sexuais e orgânicos como aspecto primordial na constituição e formação da identidade, Lacan procurou entrelaçar drives ou pulsões biológicas a processos sociais. $\underline{10} \mathrm{O}$ inconsciente estaria ligado às condições sociais e históricas da vida moderna e a Psicanálise voltar-se-ia para a interpretação das imagens que pertencessem ao mundo e suas determinações (Lacan, 1966). Recentemente o estudo 
da memória tem aparecido associado a traumas resultantes de fatos sociais (Roth, 1995; Caruth, 1995 e 1996). Halbwachs, portanto, antecedeu algumas questões importantes ao associar a memória individual a condições presente na sociedade.

Como vimos, seu trabalho também tem sido utilizado por aqueles que privilegiam o estudo de processos interacionistas. Halbwachs questionou, a meu ver corretamente, a investigação da memória a partir apenas da intuição do indivíduo ou do processo interativo de construção do passado. Ele nos explicou que as nossas lembranças do passado não dependem exclusivamente de nossas vontades, intuições ou mesmo práticas sociais. Os limites do seu trabalho encontram-se na unilateralidade com que ele associou memória a quadros sociais, o que também se reproduz em estudos recentes que enfatizam o trauma oriundo socialmente, contrapondo-o a qualquer possibilidade interpretativa. Não há utilidade em contrapormos a investigação de quadros sociais ao estudo do processo de construção de representações coletivas ou mesmo do inconsciente. É impossível para qualquer abordagem escapar à questão da subjetividade e das marcas de seu próprio tempo.

Acredito que temos diversas possibilidades de conhecimento, ainda que estas tenham seus limites. O conceito freudiano de drive, por exemplo, pode sobreviver em teorias que enfatizam que a única possibilidade de sua realização está na linguagem ou no mundo social. Paul Ricoeur argumenta que Freud, ao considerar que o "instinto" da morte — que significa uma forma de defesa orgânica a estímulos externos — precede os "instintos" do prazer e da realidade, acabou por permitir à natureza seu lugar, sem que atribuísse a ela uma determinação direta sobre formas de expressão e manifestação de comportamento. Para ele, o instinto da morte seria um "instinto" anterior e silencioso, isto é, sem expressão lingüística, em comparação aos demais (Ricoeur, 1978, p. 312, e 1979, p. 308). Apontou, com isso, a possibilidade de considerarmos simultaneamente as esferas do simbólico e do não-simbólico, dando à interpretação aberturas e variedades infinitas. O trabalho de Ricoeur exemplifica meu argumento, uma vez que, ao aceitar a associação entre o inconsciente e aspectos lingüísticos e não-lingüísticos, ele acaba por concluir que a relação entre significado e expressão não adquire uma resolução completa em si mesma.

Halbwachs, seguindo uma tendência de sua época, procurou superar as imprevisibilidades decorrentes da intuição e da subjetividade mediante a crença de que seria possível uma análise quantitativa e científica de quadros sociais da memória. Embora ele tenha nos mostrado a importância de considerarmos a presença de fragmentos do passado, de lugares sociais da memória na constituição do passado, ao voltar-se para uma abordagem científica e funcional da memória, eliminou fatores que pudessem desestabilizar sua abordagem. Argumentando que indivíduos têm a impressão de que suas memórias são únicas e coerentes porque eles necessitam desta memória para se compreenderem em seu mundo, Halbwachs considerou a memória coletiva a partir de seu papel estabilizador e como um pré-requisito funcional das sociedades. Para ele, os quadros sociais da memória podem ser estudados como objeto de investigação. Mas como ignorar que cada quadro social da memória pode ser construído por diferentes perspectivas e ser tanto integrador quanto desintegrador? Evidentemente, os quadros sociais da memória não são únicos, nem impermeáveis a interpretações conflitantes. Os quadros sociais não têm concretude ou função tal que os permita ser analisados objetivamente e segundo os rigores da análise científica; eles não se colocam acima de tensões e conflitos sociais.

Outro autor que nos permite pensar em memória e identidade sem os rigores da abordagem científica é Walter Benjamin. Suas reflexões sobre memória coletiva de certa forma lidam com os aspectos que ressaltei do trabalho de Halbwachs fora de um quadro analítico funcional ou estruturalista. Benjamin, apesar de tecer a mesma crítica de Halbwachs a filósofos, psicanalistas, escritores e pensadores que associavam a memória a uma capacidade individual de resgatar o passado, apostou na possibilidade de um confronto de experiências distintas no tempo. Estas 
encontrar-se-iam em constelações configuradas, cujo confronto permitiria a percepção da diferença e o conhecimento do passado. Embora aceitando a distância entre construções sociais e suas representações, Benjamin não desprezou a possibilidade de considerar o passado ou suas determinações, ainda que o visualizasse preso a suas fantasmagorias: construções estáticas do presente onde experiências relativas a diferentes momentos se encontravam. Ainda que com alguns paralelos com os lugares da memória investigados por Halbwachs, para Benjamin (1968) as fantasmagorias deveriam ser percebidas através do confronto de diferentes experiências no tempo e no espaço, ou seja, de imagens dialéticas.

O fundamental do conceito de Benjamin, para mim, é que, ao propor o confronto de diferentes formas de experiência humana, advindas de tempos históricos distintos, em que o conhecimento sobre o passado se realizaria (Buck-Morss, 1989), ele admite a multiplicidade da experiência humana e sua simultaneidade num mesmo momento histórico. Para Benjamin, seriam justamente as condições traumáticas da vida moderna que, ao trazerem consigo a desintegração da aura, trariam também a possibilidade do resgate do passado, ao mesmo tempo que o acerto de contas com injustiças do mesmo passado. A crítica, quando possível, aparece como resultado do confronto entre diferentes formas de ser no mundo.

Em Halbwachs encontramos as certezas do conhecimento e da verdade. Mas, em que pesem a rigidez do seu pensamento e sua necessidade de aproximar os estudos da memória das certezas aplicadas às ciências naturais, os méritos de seu trabalho sobre memória coletiva são inúmeros. Seu trabalho tem servido como fonte de aprendizado a toda uma geração de historiadores, antropólogos e sociólogos que se voltam hoje para o estudo da construção de mentalidades e identidades coletivas. Ele foi, ainda, um dos primeiros intelectuais deste século a priorizar o estudo de imagens e a inserir em sua investigação dados arqueológicos, iconográficos e arquitetônicos, ao lado de testemunhos de época. Além disso, mostrou como o estudo de lugares da memória, ao voltar-se para longos períodos de tempo, ainda é capaz de tornar evidente que as marcas deixadas pelo passado não são tão imperceptíveis e inócuas como muitos supõem. Enfim, por possibilitar uma melhor compreensão da relação entre identidade, "ego" e representações coletivas presentes nos quadros sociais da memória, seu trabalho continua a nos mostrar hoje, como mostrou no passado, que nossa capacidade de pensar, agir e transformar o mundo, seja ela estratégica, normativa ou reflexiva, necessita sempre considerar seus limites. Pois há nestes processos aspectos que, por mais que os incorporemos, nos antecedem e sobre os quais não temos total controle.

\section{NOTAS}

1 Os trabalhos hoje bastante conhecidos de Wagner (1975) e Hobsbawm e Ranger (1983) destacam-se por sua contribuição à compreensão de que identidades coletivas são construídas e reconstruídas segundo interesses determinados.

2 Embora não seja muito conhecida no Brasil, considero a coletânea organizada por David Middleton e Derek Edwards (1990) paradigmática, não só pelo estabelecimento de abordagens multidisciplinares e interacionistas das memórias coletivas, rompendo os limites entre identidade e memória coletiva, como pela associação entre construção da memória e práticas políticas.

3 Dentre os novos trabalhos sobre memória coletiva que de uma forma ou de outra mostram as associações entre as dimensões individuais, sociais e políticas, ver, por exemplo, Neisser (1982a, 1982b, 1990a e 1990b), Hobsbawm (1983), Nora (1984), Bosi (1987), Hutton (1988 e 1993), Davis (1989), Connerton (1989), Middleton e Edwards (1990), Santos (1993 e 1994), Gillis (1994), Roth (1995), Caruth (1995 e 1996).

4 Para dados biográficos sobre Halbwachs, ver Alexandre (1968), Douglas (1985 e 1986) ou, ainda, Hutton (1993).

5 No decorrer do trabalho procurarei manter o termo "quadro social da memória", deixando claro as dimensões espacial e temporal que Halbwachs atribui a este conceito.

6 Dentre os estudos que têm ressaltado a necessidade de considerarmos estes trabalhos como complementares, ver Douglas (1968 e 1986) e Bosi (1987)

7 Hutton (1988 e 1993) tem desenvolvido uma análise comparativa sistemática entre o trabalho de Halbwachs e a historiografia iniciada por Philippe Ariès, bem como sobre a proximidade entre seus trabalhos e os de Foucault no que diz respeito ao método desconstrutivista. 
8 Esta distinção entre história e memória é feita por inúmeros historiadores, mas o estudo que hoje serve como referência a este argumento é o de Pierre Nora (1984).

$\underline{9}$ Refiro-me aqui às questões de poder levantadas por Foucault (1971).

10 Uma análise da incorporação da abordagem lacaniana nos estudos da memória encontra-se em Santos (1994, pp. 83-119).

\section{BIBLIOGRAFIA}

AGOSTINHO. (1961), Confessions. Baltimore, Penguin Books. $\quad[\underline{\text { Links }}]$

ALEXANDRE,

J.-Michel.

(1968),

"Introduction", in Maurice Halbwachs, La mémoire collective, Paris, Presses Universitaires de France. [L Links ]

BARTLETT, Frederic. (1961 [1932]), Remembering: a study in experimental Social Psychology. Cambridge, Cambridge University Press. [ [ Links]

BECK, Ulrich. (1996 [1986]), Risk society: towards a new modernity. Londres, Sage Publications. [L Links ]

BENJAMIN, Walter. (1968), "On some motifs in Baudelaire", in H. Arendt (ed.), Illuminations: essays and reflections, Nova York, Harcourt, Brace \& World.

BERGSON, Henri. (1985 [1939]). Matière et mémoire. Paris, Presses Universitaires de France. [ [ Links]

BOSI, Ecléa. (1987), Memória e sociedade: lembranças de velhos. São Paulo, T.A.Queiroz/EDUSP. [ [ Links ]

BUCK-MORSS, Susan. (1989), The dialectics of seeing: Walter Benjamin and the arcades project. Cambridge, The MIT Press. $\quad[\underline{\text { Links }}]$

CARUTH, Cathy (ed.). (1995), Trauma: explorations in memory. Baltimore/ Londres, The Johns Hopkins University Press. [ [ Links ]
CARUTH, Cathy. (1996), Unclaimed experience: trauma, narrative, and bistory. Baltimore/Londres, The Johns Hopkins University Press. [ [ $\underline{\text { Links }] ~}$

CONNERTON, Paul. (1989), How societies remember. Cambridge, Cambridge University Press.

[ $\underline{\text { Links }] ~}$

DAVIS, Natalie Zemon e STARN, Randolf. (1989), "Introduction: memory and countermemory". Representations, 26: 1-6. [ [Links ]

DOUGLAS, Mary. (1968), "Introduction", in Maurice Halbwachs, The collective memory,Nova York, Harper \& Row Publishers, Inc.

. (1986), How institutions think. Londres, Routledge \& Kegan Paul.

FOUCAULT, Michel. (1971), "Nietzsche, genealogy, history", inDonald F. Bouchard (ed.), Language, countermemory, practice, Nova York, Cornell University Press, pp. 139-164. [L Links ]

GIDDENS, Anthony. (1990), The consequences of modernity. Stanford, Stanford University Press. [ [ $\underline{\underline{\text { Links }}}]$

GILLIS, John R. (1994), "Memory and identity: the history of a relationship", in John R. Gillis (ed.),Commemorations: the politics of national identity, New Jersey, Princeton University Press. $\quad[\underline{\text { Links }}]$

GOFFMAN, Erving. (1959), The presentation of self in everyday life. Nova York, Doubleday Anchor Books. [ [ $\underline{\underline{L i n k s}}$ ]

HALBWACHS, Maurice. (1925), Les cadres sociaux de la mémoire. Paris, Presses Universitaires de France. [L Links] (1939), "La mémoire collective chez les musiciens". Revue Philosophique, 127: 136-165. [ [ [ Links ] - (1941), La topographie légendaire des évangiles en Terres Saintes: étude de mémoire collective. Paris, Presses Universitaires de France. [ [Links] 
(1950), La mémoire collective. Paris, Presses

Universitaires de France. [ [ Links ]

HOBSBAWM, Eric e RANGER, Terence (eds.). (1983), The invention of tradition. Cambridge, Cambridge University Press. [ [ $\underline{\underline{L i n k s}}]$

HUTTON, Patrick H. (1988), "Collective memory and collective mentalities: the Halbwachs-Ariès connection".Historical Reflections, 15, 2: 311-322. [ [Links] (1993), History as an art of memory. Hanover/Londres, University Press of New England. [ [ $\underline{\text { Links }}]$

LACAN, Jacques. (1966), Écrits I. Paris, Éditions du Seuil. $\quad[\underline{\text { Links }}]$

MIDDLETON, David e EDWARDS, Derek. (1990), Collective remembering. Londres, Sage Publications. $[\underline{\underline{\text { Links}}}]$

NAMER, Gérard. (1987), Mémoire et société. Paris, Méridiens Klincksieck. $\quad[\underline{\underline{\text { Links}}}]$

NEISSER, Ulric. (1982a), "What are the important questions?", in Ulric Neisser (org.), Memory observed: remembering in natural contexts, Oxford, W.H. Freeman. $\quad[\underline{\text { Links }}]$

(1982b), "John Dean's memory: a case study", in Ulric Neisser (org.), Memory observed: remembering in natural contexts, Oxford, W.H. Freeman. [ [ Links]

(1990a), "New vistas in the study of memory", in Ulric Neisser e E. Winograd (orgs.), Remembering reconsidered: ecological and traditional approaches to the study of memory, Cambridge, Cambridge University Press. [L Links]

(1990b), "What is ordinary memory the memory of?", in Ulric Neisser e E. Winograd (orgs.),Remembering reconsidered: ecological and traditional approaches to the study of memory, Cambridge, Cambridge University Press, pp. 356-373. [ [

NORA, Pierre. (1984), "Entre mémoire et histoire", in P. Nora (org.), Les lieux de mémoire, vol. 1, Paris, Gallimard, pp. XVII-XLII. [L Links $]$

RICOEUR, Paul. (1978), "Image and language in Psychoanalysis", in J.H. Smith (ed.), Psychoanalysis and language, New Haven/Londres, Yale University Press. $\quad[\underline{\text { Links }}]$

(1979), "Psychoanalysis and the movement of contemporary culture", in P. Rabinow e E. Sullivan (eds.), Interpretive social sciences: a reader, Berkeley, University of California Press. [ [

ROTH, Michael S. (1995), The ironist's cage: memory, trauma, and the construction of history. Nova York, Columbia University Press. $\quad[\underline{\underline{\text { Links }}}]$

SANTOS, Myrian S. dos. (1993), "O pesadelo da amnésia coletiva: um estudo sobre os conceitos de memória, tradição e traços do passado". Revista Brasileira de Ciências Sociais, Anpocs, 23: 70-85. [ [ Links ]

(1994), Memory: social construction and critique.

Tese de doutorado, Nova York, New School for Social Research. [ $\underline{\underline{\text { Links}}}]$

WAGNER, Roy. (1975), The invention of culture. New Jersey, Englewood Cliffs. $\quad[\underline{\underline{L} \text { inks }}]$

\section{RESUMOS / ABSTRACTS / RÉSUMÉS}

Palavras-chave: Memória coletiva; Identidade; Subjetividade; Maurice Halbwachs. O artigo discute a autonomia atribuída a identidades coletivas a partir de duas questões teóricas presentes no trabalho de Maurice Halbwachs: a antecedência de quadros 
sociais da memória e a presença de lugares da memória coletiva. Embora esteja sendo bastante utilizado por aqueles que procuram um amparo teórico para a investigação do processo de construção de identidades coletivas, Halbwachs priorizou em seu trabalho a análise de quadros sociais da memória. Em que pesem a ênfase no social e a perspectiva cientificista de seu projeto, este, se considerado dentro de um quadro teórico mais amplo, é crucial para nossa compreensão de que investigações sobre o processo de memórias e identidades coletivas precisam considerar os limites inerentes à sua constituição.

Key words: Collective memory; Identity; Subjetivity; Maurice Halbwachs. The article focuses on the ascribed autonomy of collective identities, based on two theoretical points of Maurice Halbwachs's work: the priority of the social context of memory and the presence of collective memory's sites. Although it has been extensively used by those in search of a theoretical shield for the enquiry on the process of collective identity construction, Halbwachs actually attributed a greater importance in his work to the analysis of the social contexts of memory. In spite of the social focus and the scientificistic perspective of his project, if it is considered in a broad theoretical frame, his work is crucial to our understanding of the fact that inquiries on the process of memories and collective identities must take into account the limits of their own constitution.

Mots-clé: Mémoire collective; Identité; Subjectivité; Maurice Halbwachs.

L'article porte sur la soi-disant autonomie des identités collectives, à partir de deux questions théoriques présentes chez Maurice Halbwachs: la priorité des cadres sociaux de la mémoire et la présence de sites de mémoire collective. Bien qu'il soit largement utilisé par ceux qui cherchent un appui théorique pour la recherche sur le processus de construction des identités collectives, Halbwachs accorda plus d'importance dans son travail à l'analyse des cadres sociaux de la mémoire. Malgré le poids de l'aspect social et de la perspective scientificiste de son projet, celui-ci, consideré dans un contexte théorique plus étendu, est décisif pour notre compréhension du fait que des recherches sur le processus de mémoires et identités collectives doivent tenir en compte les limites propres à leur constitution. 